\title{
Penetration and Growth Rates of Mobile Phones in Developing Countries: An Analytical Classification
}

\author{
Jeffrey James
}

Accepted: 27 December 2009/Published online: 7 January 2010

(C) The Author(s) 2010. This article is published with open access at Springerlink.com

\begin{abstract}
This brief paper uses a simple arithmetic framework to classify and explain the performance of developing countries in closing the absolute digital divide. Four categories are created on the basis of two variables, namely, the penetration and rate of growth of mobile phones. The paper answers questions such as: Which countries do well and badly on both variables? Are the countries in these categories drawn from specific regions or similar income levels or is the distribution more random? How can similar countries from the same region appear in two diametrically opposite categories? What does this imply for policy?
\end{abstract}

Keywords Diffusion of mobile phones - Country performance $\cdot$ New category

There is an almost exclusive focus in debates over the digital divide on the ratio of information technology in developed countries as compared with developing countries (see for example the yearbooks published by the International Telecommunications Union (ITU) and other international institutions involved with the topic). The implication is that users of this relative digital divide are implicitly accepting that its welfare implications are more important than those associated with the absolute divide (i.e. the stock of information technology in developed countries minus the stock in developing). Yet it is far from clear that this is true. On the contrary, I argue in this paper that the absolute divide has far more important implications for welfare than the relative measure and hence that there is a need to refocus the literature in the direction of this neglected concept. I then turn to investigate how different developing countries have behaved according to this measure over a relatively recent 6 year period. First, however, let me explain why the new technology aspect of the more general divide deserves to be studied in the first place.

J. James $(\bowtie)$

Tilburg University, Tilburg, The Netherlands

e-mail: m.j.james@uvt.nl 


\section{The Importance of the Digital Divide}

Technology in general and information technology in particular constitute only one aspect of the general divide that separates rich and poor countries. But they are extremely important aspects of this gap. Technology, after all, is a factor that contributes in a major way to the difference in productivity and growth rates between developed and developing countries (as shown in the so-called empirical growth literature). The generation of new technologies occurs almost entirely in and for the former countries causing a divergence rather a convergence between these groups of countries. Information technology in the form of mobile phones and the Internet deserve particular scrutiny from this point of view. The reason is that they form part of what is known as general purpose technology (GPT) which affects not only household life but also the way in which firms from all sectors of the economy do business. Other GPT technologies include such major innovations as steam, electricity and internal combustion. As such, information technology has potentially enormous scope for raising well-being in developing countries. Reliable research in fact already indicates that mobile phones have a substantial effect on growth in developing countries and that the gains tend to accrue disproportionately in favour of the poorer members of this group (Waverman et al. 2005).

\section{Welfare Implications of the Absolute Divide}

More fundamental to welfare is a comparison of absolute numbers of users in rich and poor countries. This comparison informs us of the differential extent to which inhabitants of these regions actually benefit from mobile phones. And this ultimately is what a digital divide should reflect (James 2009). Closing the relative divide is only an intermediate step in the larger process of eliminating the absolute divide between rich and poor countries.

The heavy focus of attention on the relative divide would be less problematic if it told us something about the behavior of the absolute divide. But this is not necessarily the case. It is quite possible for example to have a falling relative magnitude and a rising divide in an absolute sense.

\section{The Behavior of the Absolute Divide}

The variables that determine the pace of this divide in the case of mobile phones are penetration and growth rates in rich and poor countries (see formula below). These variables are used here to classify and hopefully explain the performance of developing countries over a quite recent 6 year period. Which countries for example perform relatively well on both penetration and growth rates? Which do poorly on both? Are the countries in these (and other) categories drawn from specific regions or similar income levels or is the distribution more random? How can similar countries from the same region appear in two diametrically opposite categories? These are some of the entirely new questions that this paper seeks to answer. First however let me describe some basic concepts.

\section{Basic Concepts}

Recall that the absolute gap in mobile phones is defined as the stock of this technology in developed countries minus the stock in developing countries. In order to determine the 
Table 1 The behaviour of the absolute divide, 2000-2006

\begin{tabular}{ll}
\hline 1. & $\begin{array}{l}\text { Absolute digital divide increases: } \\
\text { Mobile phone stock developed countries (2006) }\end{array}$ \\
& Mobile phone stock developing country (2006) \\
2. & Absolute digital divide falls: \\
& $\frac{\text { Mobile phone stock developing country }}{\text { Mobile phone stock developing country (2006) }}<\frac{\text { growth developing country }}{\text { growthdeveloped countries }}$ \\
\hline
\end{tabular}

Source: James (2009)

behaviour of this divide over the period from say 2000 to 2006 I need to compare two ratios. One is the ratio of the stock of mobile phones in the developed countries divided by the stock in developing countries and the other is the reverse ratio of growth rates in mobile phones between the two regions over the selected period. Table 1 shows two possibilities for a given developing country: one where the absolute divide falls and the other where it increases.

Note that this method is equivalent to saying that the absolute divide rises or falls depending on whether the absolute growth of mobile phones in developed countries is greater than the absolute growth in developing countries. Consider the following example where the stock of mobile phones in the former countries is 100 and in the latter 50. Growth in phones is equal to $10 \%$ in the developing and $4 \%$ in the developed countries. This means that the absolute divide falls: there is a growth of five phones in the poor countries and four phones in the rich countries i.e.

$$
\frac{100}{50}<\frac{10}{4}
$$

Our method merely decomposes total growth of mobile phones into a stock and a flow component, which is useful when analyzing the performance of countries in later sections.

Intuitively, the idea is that for any given ratio of stocks, say ten to one, growth performance in the developing country has to be at least ten times greater than the developed countries if the divide is to shrink (and conversely). In general a narrowing of the absolute divide is more likely to occur the lower is the stock ratio and the higher is the growth differential. Developing countries will however vary in their performance along these two dimensions and this logically gives rise to the four possible combinations shown in Fig. 1.

Note that 'high' and 'low' in the figure are defined with reference to the sample average in each case. The arrow connects the two diametrically opposite quadrants, 'high-high' and 'low-low'. Let us begin by analyzing the characteristics of the countries that fall into these two extreme groups. ${ }^{1}$

\section{The Country Classification}

The sample to be classified consists of 64 countries from the low and low-middle income categories of the World Bank. ${ }^{2}$

\footnotetext{
1 The first part of the paper follows James (2009).

2 The list of countries is provided in the "Appendix". Initially, more than 64 countries were selected but the level of penetration of these additional countries at the beginning of the period was zero.
} 
Fig. 1 A simple classification scheme

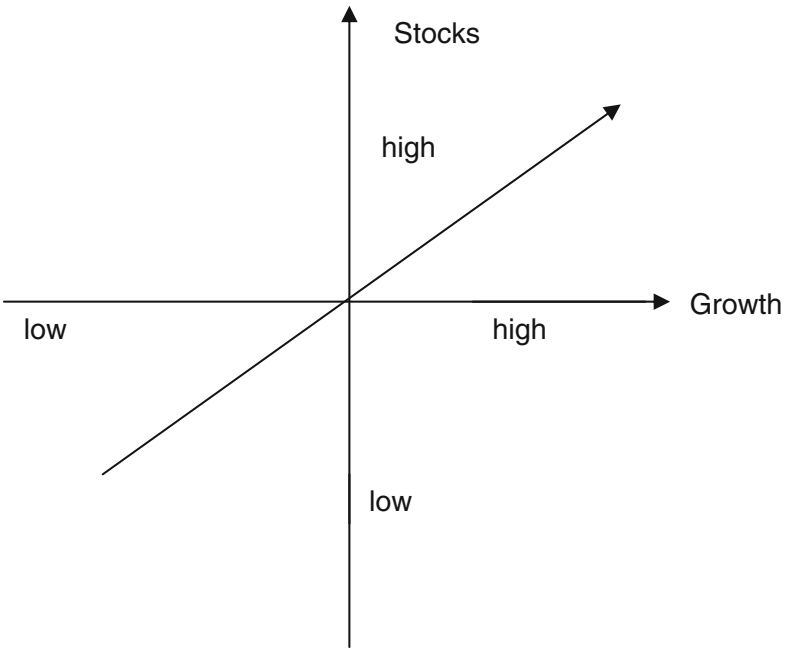

\subsection{The 'Low-Low' Category}

Table 2 presents the countries in this sample, together with their per capita income levels.

Table 2 gives a strong impression that the countries within it have not been randomly chosen. Rather, they exhibit a number of distinctive features. The first is that the countries

Table 2 Countries in the 'low-low' category, 2006

\begin{tabular}{lll}
\hline Country & Penetration rate (per 100) & Income level $(\$)$ \\
\hline Burundi & 1.9 & 100 \\
Cambodia & 8 & 490 \\
Central African Republic & 2.4 & 350 \\
Malawi & 3.2 & 230 \\
Mongolia & 21.8 & 1,000 \\
Zimbabwe & 6.3 & 340 \\
Haiti & 5.4 & 430 \\
Madagascar & 5.5 & 280 \\
Rwanda & 3.3 & 250 \\
Sierra Leone & 2.2 & 240 \\
Iraq & 2.1 & NA \\
Cuba & 1.4 & NA \\
& Average $=5.29$ & Average $=\$ 371$ \\
& Low-income countries $=14.3$ & Low-income counties $=\$ 649$ \\
& SSA (Sub-Saharan Africa) $=13.5$ & SSA (Sub-Saharan Africa) $=\$ 829$ \\
& Low-middle income $=381$ & Low-middle income $=\$ 2,038$ \\
\hline
\end{tabular}

Source: World Bank at-a-glance tables

Note: Leaving out Mongolia from the averages yields a penetration rate of 3.8 and an income level of $\$ 301$ 
listed are drawn from amongst the very poorest in the developing world (Iraq is an exception in that while it is a middle low income country, penetration has been severely hindered by the state). The second feature is that these ultra poor cases suffer from exceptionally low penetration rates (relative again to the low-income country average of the World Bank) The income level for example is well under half that of low-income countries as a whole while the same is true of the penetration rate.

The above analysis draws attention to income as being the main common factor among the countries in the 'low-low' category. This finding is very much in line with crosscountry evidence on the role of income in explaining the variation in penetration rates of the Internet and mobile phones (Dewan et al. 2004; Dasgupta et al. 2002). From the point of view of penetration rates, one might then expect the countries in the opposite 'goodgood' category to have sharply higher income levels. Such countries may indeed have escaped the form of poverty trap where low income constrains mobile phone adoption and the lack of this technology in turn keeps poverty at a high level (Countries are so poor, that is, that growth in mobile phones is impossible). Let us then examine which countries fall in the 'high-high' case and see if they conform to our expectations.

\subsection{The 'High-High' Category}

Table 3 presents the countries in this category together with their per capita income levels. In terms of the average income of $\$ 1,588.8$ there is a clear increase over the comparable figure in Table 1. Around this average, however, is a wide dispersion of incomes. On the one hand there are indeed low-middle income countries with relatively high levels such as Libya and Algeria (see more on the latter below).

Table 3 Countries in the 'high-high' category and their income levels

Source: World Bank

* In Sub-Saharan Africa

\begin{tabular}{ll}
\hline Country & Per capita income (2006) \\
\hline Afghanistan & NA \\
Albania & 2,930 \\
Algeria & 3,030 \\
Angola & 1,970 \\
Bangladesh & 450 \\
Colombia & 3,120 \\
$*$ Ghana & 510 \\
$*$ The Gambia & 290 \\
*Kenya & 580 \\
P.D.R. Lao & 500 \\
Libya & 7,290 \\
*Mali & 460 \\
*Mauritania & 760 \\
Pakistan & 800 \\
Syria & 1,560 \\
$*$ Tanzania & 350 \\
India & 820 \\
& AV. $=\$ 1,588.8$ \\
\hline
\end{tabular}


The majority of countries in Table 3 however has incomes that are not that much higher than those in Table 2 (even when Mongolia is left out of the sample). I am referring here mainly to the Sub-Saharan group marked with an asterisk, which (apart from Angola) has an average income of $\$ 452$ (I am also referring in this context to the P.D.R. of Lao and Bangladesh with incomes similar to the African average). The question is then: How can very similar countries appear in two diametrically opposite categories?

The general answer to this question is that income per head is not the only determinant of mobile phone penetration (or growth) in developing countries. Econometrically this was already clear in 2002 from the study by Dasgupta et al. which found that variations in penetration rates across countries had much to do with policy reform (and in particular with the liberalization of telecoms markets), as well as with variations in incomes 'Income remains a prime determinant of the digital divide, but our results suggest that appropriate economic and competition policies can sharply narrow the gap' (Dasgupta et al. 2002).

Consider for example the role of regulation in Kenya as compared with some of the African countries in the category. In particular,

Most African countries still have only one gateway operated by the incumbent with little or no competition. While some progressive states have opened up their markets to multiple service providers-Kenya has more than ten gateways and cheaper international calls as a result—at least four (Benin, Central African Republic, Sierra Leone and Zimbabwe) have gone in the opposite direction.

\section{(Economist Intelligence Unit 2007)}

More generally, competition increased in Kenya in the year 2000 when the privately owned mobile operator 'KenCell' was awarded the second GSM license. This policy initiative subsequently made mobile phones into Kenya's fastest growing industry. Two other African countries in Table 3, Tanzania and Ghana, ${ }^{3}$ also contain some of the most competitive mobile markets in the region. Note that in these cases GDP may be a more relevant determinant of competition than just GDP per person since a relatively large population size, especially in Kenya and Tanzania, gives rise to a more attractive market size from the point of view of foreign mobile operators. ${ }^{4}$

Among the countries outside the Africa region in Table 3, the P.D.R. of Lao also illustrates the role of competition and foreign firms in promoting the penetration and growth of mobile phones during the period at hand. In particular, after the market was opened up to competition in 2002 foreign capital began to emerge. Growth in mobile phones took off in 2003 and in the following 2 years the number of subscribers increased by a factor of seven. Another example that can be cited in this regard is Bangladesh which illustrates how a very poor developing country can find itself in the 'good-good' category. That reason is widespread sharing of mobile phones in very large numbers of villages as part of the well-known Grameen Telecom project.

The idea of the telecom project is to lend money to a [Grameen Bank] member in each village in Bangladesh for the purpose of purchasing a mobile phone. The phone owner then sells call-time to the other villagers, who, it seems, are willing to pay a relatively high proportion of their incomes on this service...

\footnotetext{
3 On Ghana's experience with liberalization see Frempong and Atubra (2001).

4 According to the International Telecommunications Union, Algeria, Kenya, Tanzania and Ghana belong to the ten largest mobile markets in Africa. See Toure (2007).
} 
Unlike many attempts to use IT for the benefit of the rural poor, the impact of Grameen Telecom extends well beyond the level of a particular village or region. In fact, some estimates suggest that $\sim 45$ million villages in Bangladesh now have access to a mobile phone, thanks to the Telecom endeavour (James 2007 p. 290). Still another example concerns India and the way in which that country has been able to facilitate network rollouts and increase coverage by allowing network sharing among mobile operators. One way in which this has occurred permits 'providers to spin off their passive network infrastructure in order to offer it to other providers in the market. This new passive network company receives good access to government subsidies in order to keep expanding its network' (Beardsley and Enriquez 2009, p. 70).

\section{High Achievers}

From among the countries listed in Table 3 it is useful to identify those where the absolute digital divide is closing most rapidly (where, that is to say, the growth rate differential in the basic formula less the ratio in stocks is highest). The countries thus identified are shown in Table 4.

By far the most striking case is Algeria where very rapid growth took place following liberalization of the state monopoly in 2000 (when the penetration rate was only $0.3 \%$ ). In Syria as well this year marked a change in government policy towards the telecommunications sector. ${ }^{5}$

\subsection{The 'High-Low' Category}

This category contains countries with relatively high penetration rates and low growth rates (see Table 5). Most notably it contains all but one of the thirteen countries from Latin America and the Caribbean, whose levels of income and rates of penetration happen to be high compared to the developing country average and the average of the previous category. ${ }^{6}$

But with higher penetration rates tend to go lower growth rates as suggested by the historical experience of the now developed countries (as shown in Fig. 2).

The point here is that when other things are equal growth is harder to achieve from a high than a low base. In addition there are at least a few countries from Latin America and The Caribbean where extensive liberalization of the telecommunications sector began rather late in the period at hand. I am referring here for example to Honduras and Nicaragua. Predictably, Sub-Saharan Africa is not well represented in this category. There are however a few exceptions, which indicate that above average penetration rates can not van be achieved at relatively low income levels (in 2006 for example Senegal had a penetration rate of $24.5 \%$ ).

\subsection{The 'Low-High' Category}

Representing the opposite combination of low penetration and high growth, the last category seems better-suited to African countries and indeed this category is made up entirely

\footnotetext{
5 See 'Information Technology Landscape in Syria,' available from http://www/.american.edu/initeb/ my6688a/telecominfra.htm (accessed February 10 2009).

6 The average per capita income of the Latin American countries is $\$ 2,308$.
} 
Table 4 The high achievers

\begin{tabular}{ll}
\hline Country & $\begin{array}{l}\text { Growth differentials } \\
\text { less stock ratio }\end{array}$ \\
\hline Algeria & 164.4 \\
Mali & 63.7 \\
Syria & 53.4 \\
Pakistan & 38.9 \\
Libya & 16.5 \\
\hline
\end{tabular}

Source: "Appendix"

Table 5 Countries in the 'high-low' category

Bolivia, Cameroon, China, Cote-d-Ivoire, Dominican Republic*, Namibia, Fiji, Mongolia, Honduras*, Indonesia, Jamaica*, Jordan, Lesotho, Nicaragua*, Paraguay*, Peru*, Philippines, Senegal, Sri Lanka, Sudan, Surinam*, Thailand, Togo, Vietnam, Zambia, Benin, Egypt, Iran

Source: "Appendix"

* Is a country in Latin America and The Caribbean

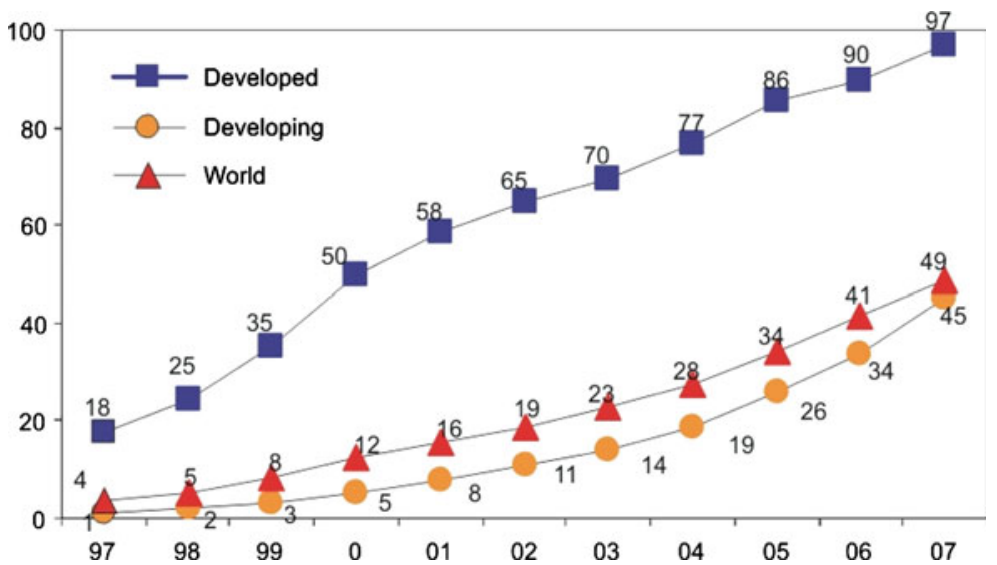

Fig. 2 Growth and penetration rates in the developed countries

of three such countries: Chad, Yemen and Burkina Faso. Africa thus becomes the only region with at least one country in each category (in contrast to Latin America and the Caribbean which is almost exclusively concentrated in just one category, as shown in the previous section).

\section{Conclusions}

This research note has used a simple arithmetic framework to classify the performance of developing countries in closing the absolute digital divide. Four categories were created on the basis of two variables, namely, the penetration of mobile phones and the rate of growth of this technology. The one extreme category, representing a below-average performance on both variables is made up primarily of especially poor developing countries, mostly from Sub-Saharan Africa. Similar countries, however, also form part of the other extreme category, where both variables perform relatively well. The anomaly was explained by 
invoking determinants of performance other than income such as the regulatory environment and market size. Of the two remaining categories the one denoting relatively high penetration and low growth contains the most entries. Almost all Latin American countries fall into this category which probably reflects the difficultly of achieving rapid growth in mobile phones when penetration levels are relatively high (here too though there were some exceptional cases). In the final category are a few African countries with low levels of mobile phone penetration but high growth rates of this technology. From a policy point of view the main conclusion is that neither the penetration nor the growth of mobile phones depends exclusively on incomes. Variables that are amenable to government influence also play a role. ${ }^{7}$

I am referring here mainly to policies such as privatization and liberalization of the telephone system that make the mobile phone market more competitive. One of the best examples in this regard is Jamaica whose growth rate in mobiles has far exceeded the growth rate achieved by most other developing countries. This exceptional performance seems to have had mainly to do with rapid liberalization of the telecommunications sector, which began in 1999 with the advent of competition in the wireless cellular market. This in turn led to lower prices and further adoption of mobile phones. Over the period between 1999 and 2005 the number of mobile phone subscribers in Jamaica grew at an annual average rate of almost $300 \%$.

Governments can also require mobile phone operators to serve rural areas since it is there that phone adoption typically lags far behind in developing countries.

Open Access This article is distributed under the terms of the Creative Commons Attribution Noncommercial License which permits any noncommercial use, distribution, and reproduction in any medium, provided the original author(s) and source are credited.

\section{Appendix}

See Table 6.

Table 6 The data-set

\begin{tabular}{lll}
\hline Country & $\begin{array}{l}\text { Growth performance* } \\
\% \text { 2000-2006 }\end{array}$ & $\begin{array}{l}\text { Penetration rate** } \\
2006\end{array}$ \\
\hline Afghanistan & 121.4 & 90.73 \\
Albania & 59.5 & 98.15 \\
Algeria & 26.3 & 98.58 \\
Angola & 84.6 & 93.43 \\
Bangladesh & 75.8 & 92.69 \\
Bolivia & 3.9 & 96.87 \\
Burkin Faso & 43.2 & 87.3 \\
Burundi & 10.7 & 52.7 \\
Cambodia & 8.8 & 88.75 \\
Cameroon & 21.4 & 92.9 \\
Central African Republic & 28.8 & 62.5 \\
Chad & 55.1 & 80 \\
China & 5.2 & 97.44 \\
\hline
\end{tabular}

\footnotetext{
7 As shown econometrically by Dasgupta et al. (2002).
} 
Table 6 continued

\begin{tabular}{|c|c|c|}
\hline Country & $\begin{array}{l}\text { Growth performance* } \\
\% \text { 2000-2006 }\end{array}$ & $\begin{array}{l}\text { Penetration rate** } \\
2006\end{array}$ \\
\hline Colombia & 102.2 & 98.63 \\
\hline Cote-d-Ivoire & 8.3 & 95.81 \\
\hline Cuba & 16.2 & 35.8 \\
\hline Dominican Republic & 6.15 & 98.12 \\
\hline Ecuador & 19.4 & 98.61 \\
\hline El Salvador & 4.7 & 98.42 \\
\hline Ghana & 4.6 & 96.07 \\
\hline Guatamala & 7.82 & 98.37 \\
\hline Guyana & 7.56 & 97.69 \\
\hline India & 4.57 & 94 \\
\hline Malawi & 8.72 & 71.9 \\
\hline Mongolia & 3.0 & 95.88 \\
\hline Namibia & 5.7 & 96.33 \\
\hline Zimbabwe & 2.5 & 85.7 \\
\hline Fiji & 3.2 & 96.38 \\
\hline The Gambia & 74.8 & 96.3 \\
\hline Haiti & 10 & 83.3 \\
\hline Honduras & 14.9 & 97.2 \\
\hline Indonesia & 18.6 & 96.86 \\
\hline Jamaica & 8.1 & 99.15 \\
\hline Jordan & 10.8 & 98.85 \\
\hline Kenya & 54.2 & 94.92 \\
\hline P.D.R. of Lao & 69.5 & 92.04 \\
\hline Lesotho & 13.1 & 92.86 \\
\hline Libya & 115.1 & 98.62 \\
\hline Madagascar & 15.9 & 83.64 \\
\hline Mali & 156.6 & 92.86 \\
\hline Mauritania & 71.4 & 97.41 \\
\hline Nicaragua & 21.8 & 97.28 \\
\hline Pakistan & 134.7 & 95.85 \\
\hline Paraguay & 3.12 & 98.32 \\
\hline Peru & 6.5 & 97.08 \\
\hline Philippines & 6.1 & 98.19 \\
\hline Rwanda & 7 & 72.7 \\
\hline Senegal & 11.6 & 96.36 \\
\hline Sierra Leone & 7.9 & 59.1 \\
\hline Sri Lanka & 14.2 & 96.7 \\
\hline Sudan & 15.4 & 92.74 \\
\hline Surinam & 8.1 & 98.72 \\
\hline Syria & 149.7 & 96.27 \\
\hline Tanzania & 14.8 & 93.84 \\
\hline Thailand & 14.8 & 98.6 \\
\hline Togo & 14.1 & 91.82 \\
\hline
\end{tabular}


Table 6 continued

\begin{tabular}{lll}
\hline Country & $\begin{array}{l}\text { Growth performance* } \\
\% \text { 2000-2006 }\end{array}$ & $\begin{array}{l}\text { Penetration rate** } \\
2006\end{array}$ \\
\hline Uganda & 15.5 & 86.57 \\
Vietnam & 21.8 & 95.11 \\
Yemen & 58.2 & 90.53 \\
Zambia & 18.5 & 93.67 \\
Benin & 17.7 & 92.56 \\
Egypt & 14 & 96.3 \\
Iraq & 25 & 57.2 \\
Iran & 15.03 & 95.39 \\
\hline
\end{tabular}

\section{References}

Beardsley, S., \& Enriquez, L. (2009). Unshackled: How regulation can amplify mobile service benefits in emerging markets. The Global Information Technology Report 2008-2009, The World Economic Forum.

Dasgupta, S., Lall, S., \& Wheeler, D. (2002). Policy reform, economic growth, and the digital divide: An econometric analysis. The World Bank.

Dewan, S., Ganley, D., \& Kraemer, K. (2004). Across the digital divide: A cross-country analysis of the determinants of IT. Working Paper, Graduate School of Management, University of California, Irvine.

Economist Intelligence Unit. (2007). Africa: Wired, July 17.

Frempong, G., \& Atubra, W. (2001). Liberalization of telecoms: The Ghanaian experience. Telecommunications Policy, 25(3), 197-210.

James, J. (2007). From origins to implications: Key aspects in the debate over the digital divide. Journal of Information Technology, 22, 284-295.

James, J. (2009). From the relative to the absolute digital divide in developing countries. Technological Forecasting and Social Change, 76(8), 1124-1129.

Toure, H. (2007). Competitiveness and ICTs in Africa, extract from the Africa Competitiveness Report.

Waverman, L., Meschi, M., \& Fuss, M. (2005). The impact of telecoms on economic growth in developing countries. The Vodafone Policy Paper Series, (3), 10-23. 